\title{
Colored rice varieties of Russian breeding in terms of grain quality for development of functional rice varieties
}

\author{
$N G$ Tumanian $^{1, *}, Z h M$ Mukhina $^{1}, L V$ Esaulova $^{1}, E Y u$ Papulova ${ }^{1}, E G$ Savenko $^{1}$, and $S$ \\ $V$ Garkusha $^{1}$ \\ ${ }^{1}$ Federal Scientific Rice Centre, Belozerny, 3, Krasnodar, 350921, Russia
}

\begin{abstract}
In order to develop rice breeding material of a functional direction, technological and biochemical grain quality traits of varieties bred by the Federal Scientific Rice Centre (Rubin, Mars, Mavr, Gagat, Yuzhnaya noch) with a colored grain pericarp, high content of anthocyanins and intended for functional nutrition were studied. The varieties were grown in the valley agrolandscape zone of Krasnodar region (Russia) in 2017-2019. The studied rice varieties are included in the State Register of Protected Breeding Achievements. The grain size by weight of 1000 absolutely dry grains (weight of 1000 a.d.g.) was determined according to GOST 10842-89, fracturing - on a DSZ-3 diaphanoscope, protein content was measured using an Infralum FT-10 device. The determination of amylose was carried out colorimetrically using the amylose-iodine reaction according to Juliano. The varieties have a medium-sized caryopsis (21.5-27.0 g of 1000 grains); of them, the variety Yuzhnaya noch is characterized by the smallest grain. The variety Mars belongs to the low amylose group, varieties Mavr, Rubin and Gagat - to the medium amylose group, Yuzhnaya noch - to the waxy group. In terms of protein content in grain, all varieties are classified as medium protein. The maximum grain fracture was in variety Mavr - in the range of $19-25 \%$ and the minimum - in Mars and Gagat, respectively 2-5 and 2-6\%. Variations in grain size indicators, amylose and protein content of varieties are weak in all varieties of special purpose, which testified to their high stability under growing conditions.
\end{abstract}

\section{Introduction}

Colored rice is consistent with the concept of food quality while meeting the demand for foods that improve the nutritional structure of the population. The ancestors of cultivated rice (Oryza sativa L.) are wild species Oryza nivara and O. rufipogon, the seeds of which have a colored pericarp. Rice with white pericarp is the result of introduction into culture, that is, the white color of rice shells appears in representatives of this genus as a result of domestication. The color of rice caryopsis (the trait is associated with antioxidant activity) is caused by pigmentation of the sclerenchyma and (or) pericarp can vary within wide

\footnotetext{
*Corresponding author: tngerag@yandex.ru
} 
limits: purple (violet, black), red, brown, yellow; variants of incomplete coloring such as spotting are possible.

Many scientific works have shown the high nutritional value of rice with a colored grain pericarp [1]. Due to the higher content of nutrients and metabolites, nutritionists strongly recommend pigmented rice for people with metabolic disorders, including diabetics, with cardiovascular diseases. In patients who ate black rice, plasma antioxidant status increased and inflammation decreased. There was also an uptake of cyanidin-3-O- $\beta$-D-glucoside (the dominant anthocyanin in black rice), which appeared in plasma and reached its maximum level $(21.5 \pm 4.48 \mathrm{ng} / \mathrm{ml})$ after 1.5 hours. Animal studies have shown a beneficial effect of consuming the colored fraction (pericarp) of rice grains in controlling blood lipids and related diseases, helping to prevent cardiovascular problems, which has been linked to various mechanisms, including increased antioxidant capacity in the body (Ling et al. , 2001), a decrease in the total concentration of cholesterol in the blood (Xia et al., 2003), a decrease in the ratio between LDL cholesterol and HDL cholesterol (Ling et al., 2001; Xia et al., 2003) [2].

Black rice includes numerous varieties with extensive historical cultivation experiences in Southeast Asian countries such as China, India and Thailand, Bangladesh, Vietnam and Indonesia. Black rice contains higher levels of protein and essential amino acids than regular rice. Cyanidin-3-glucoside accounts for $80 \%$ of the total anthocyanin content in black rice [3]. The nutritional, physico-chemical and culinary properties of four varieties of basmati rice: red basmati, white basmati, black basmati and pokhareli basmati from Nepal were studied. The maximum protein content was found in the red basmati variety $(7.74 \%)$, the minimum - in the black basmati variety (6.51\%). In Pokhareli Basmati, the total milled rice and head rice content was higher than that of other types of Basmati (72.02 \pm 0.10 and $67.46 \pm 0.42$, respectively). The core elongation coefficient and the volumetric expansion coefficient were maximum in red basmati, 1.62 and 2.85 , respectively. The water absorption coefficient was maximum, 3.11, in black basmati and minimum, 2.18, in red basmati. [4].

Rice pigmentation has been linked to the anthocyanins. The antioxidant properties of rice are widely studied. Anthocyanin (cyanidin-3-glucoside) turns the color of rice into black and therefore it is called black or purple rice (M.T. Escribano-Bailón, C. SantosBuelga, J.C. Rivas-Gonzalo, 2004; J.H. Lee, 2010) [5]. Pigmentation of seed shells is known in other agricultural cereals: when comparing closely isogenic lines of barley, differing in the gene for black color of flower scales and pericarp, an excess of antioxidant activity of extracts of grain of the line with black color was shown [6]. Anthocyanins are included in the human diet. They are used in folk and traditional medicine due to a wide range of biological activity for the prevention and treatment of diseases, including arterial hypertension, atherosclerosis, diabetes mellitus, venous insufficiency and varicose veins, gastrointestinal dysfunction, and pathology of the visual apparatus. One of the main functions of plant anthocyanin antioxidants is biological oxidation; flavonols - absorption of ultraviolet rays (protection of destructive changes in chlorophyll and cytoplasm). Various groups of flavonoids: anthocyanidins, flavones, flavonols, chalcones, aurones - are referred to as "non-plastid" pigments. Plant anthocyanidins, flavones and flavonols are usually in the form of glycosides, or less commonly as acylated derivatives or free aglycones. Anthocyanins, being the glycosides of anthocyanidins, are the largest group of water-soluble vacuolar pigments of higher plants. It is the anthocyanin pigments that determine the range of color shades: from orange-red to purple. They accumulate mostly in the generative organs - flowers and fruits. To date, more than several hundred natural anthocyanins have been identified. About 30 anthocyanidins have been isolated and identified, but about $90 \%$ of anthocyanins are based on six main anthocyanidins: pelargonidin, cyanidin, peonidin, delphinidin, petunidin and malvidin [7]. Studies carried 
out abroad on the content and profile of anthocyanins in red and black rice refer to varieties bred in Asian countries (Japan, China, Thailand, Sri Lanka, etc.) [8]. In addition, some other groups of polyphenolic antioxidants have been studied in these rice varieties, for example, proanthocyanidins, as well as lipophilic antioxidants. $[9,10,11]$. The antioxidant properties of twenty-nine red and white rice varieties from Sri Lanka and Korea were studied. Traditional red rice varieties Kalu Heeneti (TPC and ORAC), Pachchaperumal (TPC and DPPH) and Kurulu Thuda (DPPH) and OI red rice varieties H4 (FRAP) showed the highest activity in relation to the studied antioxidant properties. These varieties had a higher activity compared to black rice [12]. The increase in the pigment content was accompanied by an increase in the polyphenol content and TAC values in the colored rice grain [13]. Studies of Purpleputtu (Oryza sativa ssp. Indica cv. Purpleputtu), a unique rice from southern India that is predominantly purple in color, have shown the genetic complexity of this trait, the associated processes of domestication and deoculture during coevolution with modern varieties. Along with the genome level, allelic variations in the entire gene repertoire are associated with purple, red coloration of grain and other parts of the plant. [14].

The red color is due to the oxidation of proanthocyanidins, a class of flavonoids found in the outer layers of seeds in many species [15]. The profiles of bioactive compounds (including phenolic and flavonoid compounds in free and bound fractions, anthocyanins, proanthocyanidins, vitamin $\mathrm{E}$ and $\gamma$-oryzanol) of external and internal rice bran from six colored rice samples collected from local markets were examined. Proanthocyanidins can only be found in red rice bran, not black rice bran. [16]. Red and black rice varieties grown in northern Thailand have been studied for color and antioxidant properties. For black rice, anthocyanins were the main compound (21.15-441.96 mg / $100 \mathrm{~g}$ rice). The total content of phenol, flavonoids and tocopherol was highest in black rice, and was higher than in red rice and significantly higher than in white rice. Black rice grown in the highlands had the highest antioxidant activity compared to rice grown elsewhere [17]. Genetic and color variations in a collection of 307 samples of pigmented rice from all administrative regions of the Philippines were analyzed at PhilRice in the Philippines. Comparison with pigmented rice samples from neighboring countries Taiwan, Laos, China and India revealed a close relationship between samples from Taiwan [18].

An increase in the oxidative activity of physiological processes results in an increase in the resistance of "colored" plants to abiotic stressors. Anthocyanins absorb visible (bluegreen) light and ultraviolet radiation and, as antioxidants, contribute significantly to plant protection against excessive visible and ultraviolet radiation and photooxidative stress. Experiments were carried out on the infection of caryopses of red and black (Venere) rice Epicoccum nigrum at $10^{\circ} \mathrm{C}$ and the mycotoxigenic fungus Fusarium sporotrichioides. In both tests, red and black caryopses showed decreased or delayed infection compared to white [15].

In connection with the above, the purpose of the work was to study the genetic material of colored rice, developed at FSBSI Federal Scientific Rice Centre (Russia, Krasnodar) in relation to some technological grain quality traits and their variability in varieties grown in the valley agrolandscape zone of Krasnodar region in 2017 - 2019 as donors of valuable traits of grain quality for breeding varieties of the functional purpose.

\section{Materials and methods}

Varieties of FSRC breeding served as research material: Rubin, Mars, Mavr, Gagat, grown on the farms of the valley (Abinsky district) agrolandscape zone of Krasnodar region in 2017-2019. The seeds are presented from the USI collection (Unique scientific installation "Collection of genetic resources of rice, vegetables and melons"). The predecessor in the 
valley agrolandscape zone is agromeliorative fallow. The studied rice varieties are included in the State Register of Protected Breeding Achievements. The selection of rice grain samples was carried out in the phase of full ripeness. The soils of the plot in the Abinsky district are represented by a complex of meadow-chernozem medium-thick heavy loamy soils; the thickness of the humus horizon is $75 \mathrm{~cm}$, the humus content is $5.1 \%$, the reaction of the soil solution in the plow horizon is neutral - $\mathrm{pH}$ 6.8-7.2. The content of gross nitrogen $0.22-0.26 \%$, total phosphorus $0.18-0.20 \%$. The content of easily hydrolyzable nitrogen is $8.7-10.3 \mathrm{mg} / 100 \mathrm{~g}$; mobile phosphorus 9.3-12.2 mg / $100 \mathrm{~g}$. Mineral fertilizers were added to the top dressing in the amount of $\mathrm{N}_{60} \mathrm{P}_{90} \mathrm{~K}_{60}$ (variant 1 of the experiment) and $\mathrm{N}_{120} \mathrm{P}_{90} \mathrm{~K}_{60}$ (variant 2 of the experiment).

The grain size was determined by the weight of 1000 absolutely dry grains (weight of 1000 a.d.g.) - according to GOST 10842-89, fracturing - on a DSZ-3 diaphanoscope. The determination of amylose was carried out colorimetrically, using the amylose-iodine reaction according to Juliano: the grain starch of rice samples was gelatinized using a onemolar $\mathrm{NaOH}$ solution, transferred to an acidic medium, and reacted with iodine. The blue color of the solution after reaction with iodine was evaluated on a Genesis 8 spectrophotometer at $600 \mathrm{~nm}$. Mixed amylose / amylopectin standards were used to calculate the amylose content [19]. The protein content was measured using an Infralum FT-10 device. Mathematical and statistical data processing was carried out by calculations in Microsoft Excel.

\section{Results and discussion}

In the Federal Scientific Rice Centre (Krasnodar), over the past 20 years, rice varieties with a colored grain pericarp have been developed. Some of them, with valuable agrobiological traits, were transferred to the Federal State Budgetary Institution "State Commission of the Russian Federation for the Testing and Protection of Breeding Achievements" (Federal State Budgetary Institution "State Varietal Commission"). The varieties registered in the State Register of Protected Breeding Achievements are presented in table 1.

The object of the study were the technological and biochemical grain quality traits of special-purpose rice varieties and their variability.

Of these, three varieties Mars, Rubin and Ryzhik have a red color of the pericarp and seed coat, and three varieties Gagat, Yuzhnaya noch and Mavr have violet (purple) or black color (fig. 1).

Table 1. Colored rice varieties of FSRC breeding, Krasnodar.

\begin{tabular}{|c|c|c|c|}
\hline Variety & $\begin{array}{c}\text { Patent for a protected } \\
\text { breeding achievement }\end{array}$ & Color of pericarp & Amylose content \\
\hline Mars & $\begin{array}{c}\text { № 6525 dated } \\
31.08 .2012\end{array}$ & red & low amylose \\
\hline Rubin & $\begin{array}{c}\text { № 6526 dated } \\
31.08 .2012\end{array}$ & red & medium amylose \\
\hline Ryzhik & $\begin{array}{c}\text { № 7644 dated } \\
\text { 30.12.2014 }\end{array}$ & red & medium amylose \\
\hline Mavr & $\begin{array}{c}\text { № 7565 dated } \\
03.12 .2014\end{array}$ & purple (black) & medium amylose \\
\hline Yuzhnanya noch & $\begin{array}{c}\text { № 7566 dated } \\
03.12 .2014\end{array}$ & purple (black) & glutinous \\
\hline Gagat & $\begin{array}{r}\text { № 7642 dated } \\
30.12 .2014\end{array}$ & purple (black) & medium amylose \\
\hline
\end{tabular}




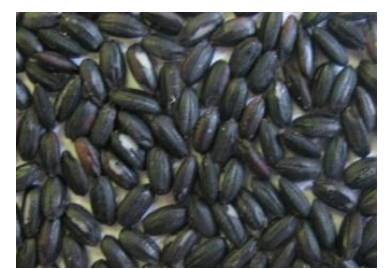

(a) Yuzhnaya noch

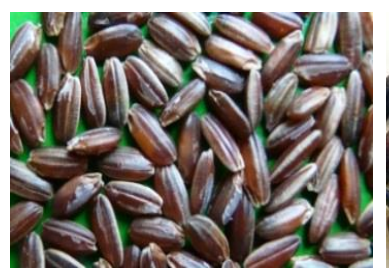

(b) Rubin

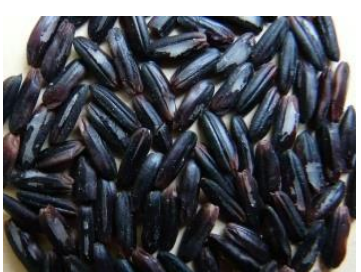

(c) Gagat

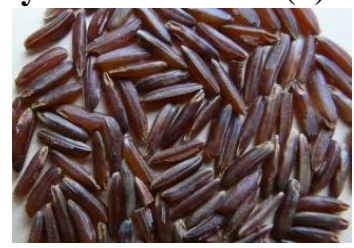

(d) Mar

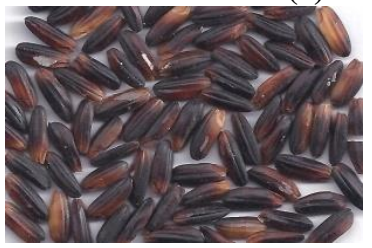

(e) Mavr

Fig. 1. Colored rice varieties of Russian breeding.

Colored rice varieties, according to the results of studies, are characterized by various technological and biochemical grain quality traits (table 2 ).

The red-grain variety Rubin ( $/$ b 2.2) and the black-grain variety Mavr (1 / b 2.5), based on the ratio of the grain length to its width, $1 / \mathrm{b}$, belong to the group of medium-grain rice varieties. Red-grain variety Mars and black-grain variety Gagat - to the group of long-grain (1 / b 3.3-3.4), black-grain variety Yuzhnaya noch - to short-grain (1 / b 2.0). The varieties have a medium-sized caryopses (21.5-27.0 g of 1000 grains); of them, the variety Yuzhnaya noch is characterized by the smallest grain. According to the content of the starch fraction - amylose, the varieties are different, which determines their different culinary advantages. Variety Mars - belongs to the group of low amylose, varieties Mavr, Rubin and Gagat - to the group of medium amylose, variety Yuzhnaya noch - to the waxy group, which becomes sticky when cooked. In terms of protein content in grain, all varieties are classified as medium protein.

The grain size of all varieties was classified as medium. In the second variant, the weight of the caryopsis slightly increased in the variety Rubin, and remained at the same level in Mavr. Fracturing in Rubin and Mars in 2018 was slightly higher than in 2019 and 2017, and in the black-grain varieties Mavr, Gagat and Yuzhnaya noch it was the highest in 2019. The change in the grain size in Rubin, due to the different level nitrogen nutrition, unlike other varieties, was insignificant. In the variety Yuzhnaya noch, only in 2017, the difference in size was significant.

The most important technological grain quality trait "fracturing" allows predicting the quality of produced rice products and determines the profitability of rice production. In the breeding process, the trait of fracturing is assessed at all stages in order to reduce its indicators in various agro-climatic growing conditions. The grain fracture is an integral indicator of the endosperm structure. The high grain quality is considered primarily due to the stability of varieties under changing conditions during the period of yield formation and the ability of the variety to maintain the integrity of the caryopsis without cracks. Colored rice varieties in the study showed different fracturing rates. The maximum grain fracturing was in the variety Mavr - within 19-25\% and the minimum - in Mars and Gagat, respectively $2-5$ and $2-6 \%$. In 2017, all varieties had fracturing higher in comparison with the indicators of 2018 and 2019. In the varieties Rubin and Gagat, the grain fracture decreased by $2-8 \%$ with an increase in the nitrogen dose, in Mars it practically did not change, and in varieties Mavr and Gagat it increased. 
Table 2. Quality traits of special-purpose rice varieties, yield of 2017-2019.

\begin{tabular}{|c|c|c|c|c|c|c|}
\hline Variety & Year & Variant & $\begin{array}{l}\text { Weight of } \\
1000 \text { a.d. } \\
\text { grains, g }\end{array}$ & $\begin{array}{c}\text { Fracturing, } \\
\%\end{array}$ & $\begin{array}{c}\text { Amylose } \\
\text { content, } \\
\%\end{array}$ & $\begin{array}{c}\text { Protein } \\
\text { content, } \\
\%\end{array}$ \\
\hline \multirow{6}{*}{ Rubin } & \multirow{2}{*}{2019} & 1 & 25.1 & 15 & 21.8 & 8.4 \\
\hline & & 2 & 25.1 & 8 & 22.4 & 8.2 \\
\hline & \multirow{2}{*}{2018} & 1 & 25.9 & 9 & 21.5 & 8.7 \\
\hline & & 2 & 26.0 & 7 & 21.3 & 8.9 \\
\hline & \multirow{2}{*}{2017} & 1 & 25.0 & 14 & 21.2 & 8.9 \\
\hline & & 2 & 25.0 & 8 & 21.3 & 8.9 \\
\hline \multirow{6}{*}{ Mars } & \multirow{2}{*}{2019} & 1 & 24.0 & 4 & 17.7 & 7.0 \\
\hline & & 2 & 24.3 & 4 & 17.2 & 7.3 \\
\hline & \multirow{2}{*}{2018} & 1 & 24.6 & 3 & 17.7 & 7.2 \\
\hline & & 2 & 24.8 & 3 & 17.2 & 7.4 \\
\hline & \multirow{2}{*}{2017} & 1 & 24.3 & 5 & 17.3 & 7.6 \\
\hline & & 2 & 24.5 & 4 & 17.1 & 7.8 \\
\hline \multirow{6}{*}{ Mavr } & \multirow{2}{*}{2019} & 1 & 24.8 & 19 & 22.4 & 8.0 \\
\hline & & 2 & 25.3 & 22 & 22.3 & 8.0 \\
\hline & \multirow{2}{*}{2018} & 1 & 24.4 & 23 & 21.9 & 8.4 \\
\hline & & 2 & 24.6 & 25 & 21.6 & 8.6 \\
\hline & \multirow[b]{2}{*}{2017} & 1 & 23.8 & 22 & 21.6 & 8.7 \\
\hline & & 2 & 23.9 & 24 & 21.3 & 8.9 \\
\hline \multirow{6}{*}{ Gagat } & \multirow{2}{*}{2019} & 1 & 26.6 & 3 & 21.7 & 8.8 \\
\hline & & 2 & 26.9 & 6 & 21.3 & 9.0 \\
\hline & \multirow{2}{*}{2018} & 1 & 26.4 & 2 & 21.6 & 9.0 \\
\hline & & 2 & 26.6 & 5 & 21.2 & 9.2 \\
\hline & \multirow{2}{*}{2017} & 1 & 26.5 & 2 & 21.3 & 9.2 \\
\hline & & 2 & 26.5 & 4 & 21.4 & 9.2 \\
\hline \multirow{6}{*}{$\begin{array}{l}\text { Yuzhnaya } \\
\text { noch }\end{array}$} & \multirow{2}{*}{2019} & 1 & 19.8 & - & 0.0 & 8.0 \\
\hline & & 2 & 19.8 & - & 0.0 & 8.4 \\
\hline & \multirow{2}{*}{2018} & 1 & 19.6 & - & 0.0 & 8.3 \\
\hline & & 2 & 19.7 & - & 0.0 & 8.3 \\
\hline & \multirow{2}{*}{2017} & 1 & 19.6 & - & 0.0 & 8.7 \\
\hline & & 2 & 19.8 & - & 0.0 & 8.7 \\
\hline $\mathrm{LSD}_{05}$ & & & 0.15 & 1.5 & 0.4 & 0.15 \\
\hline
\end{tabular}

Amylose and protein content in the endosperm of rice caryopsis are the most important biochemical traits of the variety. The milled rice quality and the use of the variety in specific culinary dishes is determined by the ratio of amylose and amylopectin in the grain starch and the protein content. The difference in the amylose content over the years of the study in the options for nitrogen doses between the maximum and minimum values was $0.6 \%$ for the varieties Rubin, Mars, $1.1 \%$ for Mavr, $0.5 \%$ for Gagat. A tendency of a decrease in the amylose content in grain under conditions of an increase in the nitrogen dose was noted in varieties, except for Rubin. In 2019, with an increase in the level of nitrogen fertilizers, the amylose content increased. Protein content in varieties under conditions of lower nitrogen supply decreased by $0.2 \%$ or more or remained at the same level. However, in the variety Rubin, it increased in 2019. 
The study of the variability of rice varieties by quality traits makes it possible to predict the quality of the yield grown in different agro-climatic conditions of cultivation and rice products produced from grain, to optimize the cultivation technologies.

The following results were obtained from the study of the proportion of contributions of the factors "variety" (A) and "level of mineral nutrition" (B), "year" (C) (table 3). The shares of the contributions of the "variety" trait in the formation of the variability of the grain size turned out to be insignificant, and the fracturing was at an average level (35.30). The share of the contribution of factor $\mathrm{B}$ and factor $\mathrm{C}$ to the formation of variability of quality traits was insignificant for all varieties.

Table 3. Shares of contributions of factors "variety" (A) and "level of mineral nutrition" (B), "year" (C).

\begin{tabular}{|c|c|c|}
\hline \multirow{2}{*}{ Variation source } & \multicolumn{2}{|c|}{ Share of contribution, \% } \\
\cline { 2 - 3 } & weight of 1000 a. d. g. & fracturing \\
\hline Factor A & 3,20 & 35,30 \\
\hline Factor B & 2,52 & 18,31 \\
\hline Factor C & 5,46 & 17,2 \\
\hline
\end{tabular}

Variation of a trait, which characterizes the variability of a variety for a trait, is usually estimated by the coefficient of variation and is considered weak with a coefficient of variation less than or equal to $10 \%$, medium - with a coefficient of variation $10-33.3 \%$, strong - more than $33.3 \%$. Table 4 shows the average values and variability of quality traits of rice varieties.

Table 4. Mean values and variabity of grain quality traits of rice varieties Rubin, Mars, Mavr, Gagat, Yuzhnaya noch.

\begin{tabular}{|c|c|c|c|c|c|c|c|c|}
\hline \multirow{3}{*}{ Variety } & \multicolumn{8}{|c|}{ Variability of technological quality traits } \\
\hline & \multicolumn{2}{|c|}{$\begin{array}{l}\text { weight of } 1000 \text { a.d. } \\
\text { grains }\end{array}$} & \multicolumn{2}{|c|}{ fracturing } & \multicolumn{2}{|c|}{ amylose content } & \multicolumn{2}{|c|}{ protein content } \\
\hline & $\begin{array}{c}\mathrm{M}^{\mathrm{a}} \\
\mathrm{g}\end{array}$ & $\begin{array}{c}\mathrm{CV}^{\mathrm{b}}, \\
\%\end{array}$ & $\begin{array}{l}\text { M., } \\
\%\end{array}$ & $\begin{array}{c}\mathrm{CV} \\
\%\end{array}$ & $\begin{array}{l}\text { M., } \\
\%\end{array}$ & $\begin{array}{c}\mathrm{CV} \\
\%\end{array}$ & $\begin{array}{l}\text { M., } \\
\%\end{array}$ & $\begin{array}{c}\mathrm{CV} \\
\%\end{array}$ \\
\hline Rubin & 25,4 & 1,85 & 10 & 25,7 & 21,6 & 2,10 & 8,7 & 3,47 \\
\hline Mars & 24,4 & 1,14 & 4 & 19,6 & 17,4 & 1,53 & 7,4 & 3,87 \\
\hline Mavr & 24,5 & 2,31 & 3 & 9,2 & 21,9 & 1,98 & 8,4 & 4,42 \\
\hline Gagat & 26,6 & 0,65 & 4 & 44,5 & 21,4 & 0,91 & 9,1 & 1,80 \\
\hline $\begin{array}{c}\text { Yuzhnaya } \\
\text { noch }\end{array}$ & 19,7 & 0,50 & - & - & - & - & 8,4 & 3,19 \\
\hline $\begin{array}{c}\text { By } \\
\text { varieties }\end{array}$ & 23,80 & 12,02 & 8,08 & 80,50 & 16,44 & 51,03 & 8,39 & 7,33 \\
\hline & & & 1 & of & & & & \\
\hline
\end{tabular}

Comparison with the average level of a trait in relative terms makes it possible to assess the stability of varieties for each trait: varieties are characterized by high stability with low values of variability of the trait. Variations in the grain size of varieties are weak in all special purpose varieties. Variations in biochemical characteristics are also weak: for amylose - from 0.91 to $2.10 \%$, for protein - from 1.80 in Gagat to $4.42 \%$ in Mavr. On the basis of grain quality trait "fracturing" the least stability was shown by the variety Gagat (coefficient of variation of the average level) and the most stable variety was Mavr.

Thus, a low variation of the traits mass of 1000 a.d.g., amylose and protein content and increased - of the trait "fracturing" is shown. It was not possible to single out the best variety according to the stability of traits and their absolute values: all varieties were classified as varieties with high technological quality traits (medium size, low fracturing), 
with different contents of amylose and protein. The variety Gagat had the highest protein content $(9.1 \%)$.

\section{Conclusions}

Rice varieties with colored grain pericarp, bred in FSRC, are characterized by different physicochemical properties of grain, have high quality characteristics and are intended for the preparation of various culinary products of the functional group.

The relevance of long-term studies of quality traits of special-purpose varieties with a colored pericarp is determined both by the tasks of developing products of high nutritional value, and by starting breeding programs for developing rice varieties of a functional direction and the development of optimal modes of their cultivation in production. The development of technological modes for growing varieties of the functional direction is determined by the reactions of the variety to the doses of fertilizers used in relation to the yield and its quality. The research obtained the results of studying the variability of the quality of rice varieties Rubin, Mars, Mavr, Gagat, Yuzhnaya noch, which are used in breeding programs for developing varieties of the functional direction, in relation to the grain size, grain fracturing, amylose and protein content for three years when using various doses of nitrogen fertilizers. Grain size in all varieties was classified as medium and with an increase in the nitrogen dose the weight of the grain slightly increased. Fracturing in the variety Mavr increased, while in the other varieties it decreased with an increase in the nitrogen dose. The regularity of changes in the protein and amylose content was noted as the opposite: with an increase in the dose of fertilizers, as a rule, with a few exceptions, the protein content in the grain of the varieties increased, and amylose - decreased. According to the results of the study, special-purpose varieties, as possessing high technological grain quality traits, various protein and amylose content in grain, as traits of nutritional value, are recommended to be used in the breeding process as donors of valuable quality traits.

The paper was prepared with the support of Kuban scientific Foundation (Project "Development and implementation of an innovative selection scheme for creating new-generation rice varieties with antioxidant activity of grain for functional nutrition based on an integrated approach combining classical breeding methods, genomic, cellular and digital technologies" MFI-20.1-20/20).

\section{References}

1. Rajni M and Usha R 2016 J. of Life Sc. 8 12-8

2. Walter M and Marchesan E 2011 Br. Arch. of Biol. and Tech.. 54(2) 371-7 doi: 10.1590/S1516-89132011000200020

3. Prasad B J, Sharavanan P S and Sivaraj R 2019 Gr. \& Oil Sc. and Tech. 2b 109-13 https://doi.org/10.1016/j.gaost.2019.09.005

4. Ojha P, Chaudhary O, Subedi U, Karki R and Dongol D M S 2018 J. of Nep. Agr. 4(1) 18-24 DOI 10.3126/jnarc.v4i1.19686

5. Prasad B J, Sharavanan P S and Sivaraj R 2019 Gr. \& Oil Sc. and Tech. 2(4) 109-13 https://doi.org/10.1016/j.gaost.2019.09.005

6. Glagoleva A Y, Shmakov N A, Shoeva O Y, Vasiliev G V, Shatskaya N V, Börner A et al 2017 BMC Plant Biol. 17182 https://doi: 10.1186/s12870-017-1124

7. Goulas V, Vicente A R and Manganaris G A Nov 2012 Sc. Publ. Inc. 225-50

8. Sompong R, Siebenhandl-Ehn S, Linsberger-Martin G and Berghofer E 2011 F. Chem.124(1) 132-40 https://doi.org/10.1016/j.foodchem.2010.05.115 
9. Jang S and Xu Z. 2009 J.of Agr. and F. Chem. 57 858-62

10. Gunaratne A, Wu K, Li D, Bentota A, Corke H and Yi-Zhong C 2013 F. Chem. 138 1153-61

11. Min B, McClung A M and Chen Min M N 2011 J. of F. Sc. 76 117-26

12. Walimuni K, Subhashini M A, Udawaththa Gunasekara K D S S, Arachchige S P G and Walimuni $\mathrm{P} \quad \mathrm{K} \quad \mathrm{M} \quad \mathrm{A} \quad 2017 \quad J$. of $C$. Lif. Med. 5(11) 480-5 DOI 10.12980/jclm.5.2017J7-113

13. Hosoda K, Sasahara H, Matsushita K, Tamura Ya, Miyaji M and Matsuyama H $2018 \mathrm{~J}$. of An. Sc. 31(8) 1213-20 DOI 10.5713/ajas.17.0655

14. Reddy Lachagari V B, Gupta R, Gupta R, Lekkala S P, Mahadevan L, Mahadevan L, Kuriakose B, Kuriakose B, Chakravartty N, Mohan Katta A. V. S. K., Santhosh S, Reddy A R and Thomas G 2019 Fr. in Pl. Sc. 10 DOI 10.3389/fpls.2019.00513

15. Gianinetti A, Finocchiaro F, Maisenti F, Kouongni Satsap D, Morcia C, Ghizzoni R and Terzi V 2018 J. of F. 4(2) 71 DOI 10.3390/jof4020071

16. Huang Yu-P.and Lai H-M 2016 J. of F. and Dr. Anal. 24(3) 564-74 DOI 10.1016/j.jfda.2016.01.004

17. Pramai Ph and Jiamyangyuen S 2016 S. J. of Sc. and Tech. (SJST) 38(5) 463-72 DOI 10.14456/sjst-psu.2016.62

18. Mbanjo E G N, Jones H, Caguiat X G I, Carandang S, Ignacio J C, Ferrer M C, Boyd L A and Kretzschmar T 2019 Rice 12(1) 1-18 https://doi: 10.1186/s12284-019-0281-2

19. ISO 6647-1:2007* Rice - Part 1 